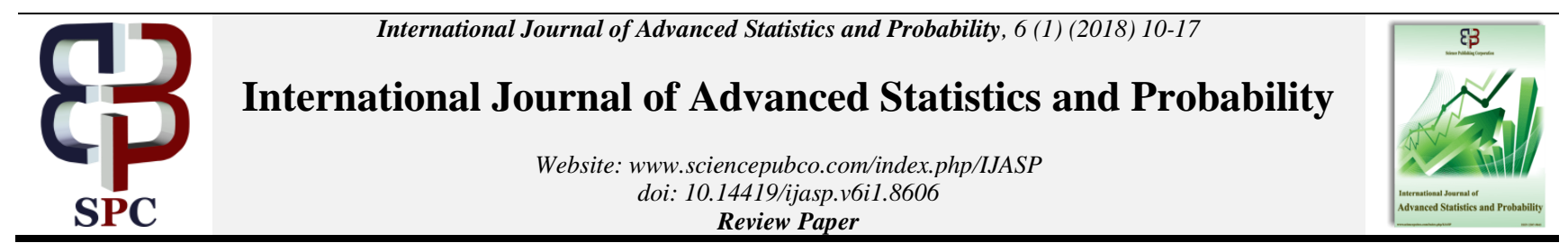

\title{
Methods for choice of model in descriptive time series : A review with example
}

\author{
Enegesele D. ${ }^{1 *}$, Iwueze I.S. ${ }^{2}$ Ijomah M.A. ${ }^{1}$, Owolabi T.W ${ }^{2}$ \\ ${ }^{1}$ Department of Mathematics/Statistics, University of Port Harcourt, Port Harcourt, Nigeria \\ ${ }^{2}$ Department of Statistics, Federal University of Technology, Owerri, Nigeria \\ *Corresponding authorE-mail: zubikeijomahs@yahoo.com
}

\begin{abstract}
This paper is a review of existing methods with illustrative examples for choice of model in descriptive time series. The methods reviewed are three graphical methods, X-12 ARIMA method and the method of seasonal differences and quotients. For each method, the same illustrative example and simulated data were used to demonstrate each method. The results obtained from the various methods using simulated additive and multiplicative series show that the various methods identified correctly the appropriate model for decomposition. Also, applying the various methods to quarterly sales of petroleum products from 2004-2013, the result reviewed that the appropriated model for decomposition of the series is the multiplicative model.
\end{abstract}

Keywords: Descriptive Time Series; Trend; Seasonality; Choice of Model; Seasonal Differences; Seasonal Quotients.

\section{Introduction}

Identification of patterns and choice of model in time series data is critical to facilitate forecasting. Two patterns that may be presented are trend and seasonality and the two competing models are the additive and multiplicative models Iwueze and Nwogu, [13]. Descriptive time series also known as the decomposition of time series is the separation of the observe time series into four components represented by the trend $\left(T_{t}\right)$, seasonal $\left(S_{t}\right)$, cyclical $\left(C_{t}\right)$ and the irregular $\left(e_{t}\right)$ components. Identification of the trend information helps to measure the trend and its removal help to analyse other fluctuations Chatfield [5]. One of the advantages for decomposition is to estimate seasonal effect that can be used to create and present seasonally adjusted values.

Decomposition models are typically additive or multiplicative, but can also take other forms such as pseudo-additive (combining the elements of both the additive and multiplicative models). For short term series, the cyclical is embedded in the trend Chatfield [5]. These models are;

Additive Model:

$X_{t}=M_{t}+S_{t}+e_{t}$

Multiplicative Model:

$X_{t}=M_{t} \times S_{t} \times e_{t}$

Pseudo-Additive:

$X_{t}=M_{t} \times S_{t}+e_{t}$
Where $M_{t}$ is the trend-cycle component; $S_{t}$ is the seasonal component and $e_{t}$ is the irregular or random component. For the additive model (1.1), it is assumed that the error component $e_{t}$ is the Gaussian white noise $N\left(0, \sigma_{1}^{2}\right)$ and the sum of the seasonal component over a complete period is zero $\left(\sum_{j=0}^{s} S_{j}=0\right)$. While for the multiplicative model (1.2), $e_{t}$ is the Gaussian white noise $N\left(1, \sigma_{2}^{2}\right)$ and the sum of the seasonal component over a complete period is $\mathrm{s}\left(\sum_{j=0}^{s} S_{j}=s\right)$

An important part of the analysis of a time series is the selection of a suitable model for decomposition. The aim of this paper is to present the various methods used in the choice between additive and multiplicative models in time series decomposition. The rational for this paper is that most existing methods are subjective and tedious. Hence there is need for alternative method that can easily aid the choice between additive and multiplicative model in time series decomposition.

\section{Buys- ballot representation of seasonal time series}

A Buys-Ballot table summarizes data to show seasonal variation (Table 1). Each line in the table is one period (usually a year) and each column is a season of the period/year (12 months, 4 quarter 52 week etc). A cell, (i,j), of this table contain the mean value for all observations made during the period $i$ at the seasonal $\mathrm{j}$. To analyse the data, it is helpful to include the period and seasonal totals $\left(T_{i}\right.$ and $\left.T_{. j}\right)$, period and seasonal averages $\left(\bar{X}_{i}\right.$ and $\left.\bar{X}_{. j}\right)$. According to Wei [19], the arrangement of data in this manner in a table is credited to Buys-Ballot [4]. Hence, the table has been called the Buys-Ballot table in the literature. To increase the utility 
of the table for the purpose of this paper, we have introduced the mean and seasonal standard deviation $\left(\bar{X}_{j,}\right.$ and $\left.\hat{\sigma}_{j}\right)$ as part of the
Buys-Ballot table.

Table 1: Buys-Ballot Table

\begin{tabular}{|c|c|c|c|c|c|c|}
\hline Period $(i)$ & Seasons & & & & & \\
\hline & 1 & 2 & $\ldots$ & $\mathrm{J}$ & $\ldots$ & $S$ \\
\hline 1 & $X_{11}$ & $X_{12}$ & $\ldots$ & $X_{1 j}$ & $\ldots$ & $X_{1 s}$ \\
\hline 2 & $X_{21}$ & $X_{22}$ & $\ldots$ & $X_{2 j}$ & $\ldots$ & $X_{2 s}$ \\
\hline 3 & $X_{31}$ & $X_{32}$ & $\ldots$ & $X_{3 j}$ & $\ldots$ & $X_{3 s}$ \\
\hline$\ldots$ & $\ldots$ & $\ldots$ & $\ldots$ & $\ldots$ & $\ldots$ & $\ldots$ \\
\hline$i$ & $X_{i 1}$ & $X_{i 2}$ & $\ldots$ & $X_{i j}$ & $\ldots$ & $X_{i s}$ \\
\hline$\ldots$ & $\ldots$ & $\ldots$ & $\ldots$ & $\ldots$ & $\ldots$ & $\ldots$ \\
\hline$T$ & $X_{m 1}$ & $X_{m 2}$ & $\ldots$ & $X_{m j}$ & $\ldots$ & $X_{m s}$ \\
\hline$\hat{\sigma}$ & $T_{.1}$ & $T_{.2}$ & $\ldots$ & $T_{. j}$ & $\ldots$ & $T_{s}$ \\
\hline $\bar{X}_{. j}$ & $\bar{X}_{1}$ & $\bar{X}_{2}$ & $\ldots$ & $\bar{X}_{. j}$ & $\ldots$ & $\bar{X}_{s}$ \\
\hline$\hat{\sigma}_{j}$ & $\hat{\sigma}_{.1}$ & $\hat{\sigma}_{2}$ & $\ldots$ & $\hat{\sigma}_{j,}$ & $\ldots$ & $\hat{\sigma}_{s}$ \\
\hline
\end{tabular}

Source: Iwueze and Nwogu (2014).

where $X_{i j}=X_{(i-1) s+j}, i=1,2, \ldots, m, j=1,2, \ldots, s$ is the series, $m$ is the number of periods/years, $s$ is the periodicity, and $n=m s$ is the overall number of observation/sample size.

$T_{j}=$ Total for $j$ th season, $\bar{X}_{. j}=$ Average of $j$ th season

$\hat{\sigma}_{. j}=$ Standard deviation for $j$ th season

For easy understanding of Table 1 we will in this paper work define the column averages and standard deviation as follows:

$$
\begin{aligned}
& \bar{X}_{j}=\frac{T_{j}}{m}=\frac{1}{m} \sum_{i=1}^{m} X_{(i-1) s+j}, j=1,2, \ldots, s \\
& \hat{\sigma}_{j}=\sqrt{\frac{1}{m-1} \sum_{i=1}^{m}\left(X_{(i-1) s+j}-\bar{X}_{j j}\right)^{2}}, \quad j=1,2, \ldots, s
\end{aligned}
$$

\section{The graphical methods}

The most use method for choice of model in descriptive time series is the graphical method. Brockwell and Davis [2], use the time plot of the entire series to choose a particular model for decomposition. The multiplicative model was adopted when the magnitude of the seasonal pattern in the data depends on the magnitude of the series. In other words, the magnitude of the seasonal pattern increases as the data value increases and decreases as the data value decreases. The additive model was adopted when the magnitude of the seasonal pattern does not change as the series goes up and down. Chatfield [5] noted that if the seasonal variation stays roughly the same size regardless of the mean level, then it is additive but if it increases in size in direct proportion to the mean level, the appropriate model for decomposition is the multiplicative models.

A better interpretation of the methods of Brockwell and Davis, and Chatfield [2], [5] is given in Iwueze et al. [12]. Instead of using the seasonal pattern as display by the time series plot of the entire series, they used the relationship between the plot of the seasonal means and seasonal standard deviation derived from the Buys-Ballot Table (see Table 1). A plot of the seasonal means $\left(\bar{X}_{j, j}\right)$ against the periodicity (s) is compared with the plot of the seasonal standard deviation $\left(\hat{\sigma}_{i}\right)$ against the periodicity $(\mathrm{s})$. They noted that the additive model be used for decomposition when the seasonal standard deviation shows no appreciable increase/decrease with respect to any increase or decrease in the seasonal means. The multiplicative model is used for decomposition when the seasonal standard deviation shows appreciable increase/decrease with respect to any increase or decrease in the seasonal means.

Dagum [8] suggested the use of X-12 ARIMA package for the choice of appropriate model for decomposition. The X-12 ARIMA has flexible capabilities for handling calendar effects, better diagnostics for handling large numbers of series. The X-12 ARIMA seasonal adjustment extract the different components (Trend, Seasonal, Cyclical and Irregular component) for a monthly or quarterly time series data. In adjusting the data for seasonal variations, a major concern is whether to decompose the series with additive or multiplicative decomposition Findley et al.[9]. The procedures make additive or multiplicative adjustment and create an output data set containing the adjusted time series. The decomposition is done with a combination of moving average filters called X-11 Shiskin et al [18]. With the multiplicative decomposition, the seasonal factors are centered on one, always positive, and divided into the original series. With additive decomposition, the seasonal factors are centered on zero and subtracted from the original series. The X-12 ARIMA is an inbuilt function in E-view statistical software. Dagum [8] noted that the decomposition for both additive and multiplicative models should be done separately. The choice for appropriate model should be base on the decomposition model that yields the higher stable seasonality F-value.

\section{Method of coefficient of variation of season- al differences and quotients}

The method of coefficient of variation of seasonal differences and quotients is well described in Justo and Rivera [14]. The seasonal differences was computed by taking the difference between a certain season of a year and the same season from the year before while the seasonal quotient was computed as the quotient of a certain season of a year and the same season from the year before. The seasonal differences and quotients are better described by using the notation in Table 1 . That is,

Seasonal Difference $\left(D_{i j}\right)$ was define as

$D_{i j}=X_{i j}-X_{(i-1) j}$

And seasonal quotient

$Q_{i j}=\frac{X_{i j}}{X_{(i-1) j}}$

Thereafter the coefficient of variation of the seasonal differences $(c v(d))$ and the coefficient of variation of the seasonal quotients $(c v(q))$ are computed as 


$$
\begin{aligned}
& C V(d)=\frac{s \tan \text { dard deviation }\left(D_{i j}\right)}{\text { Average }\left(D_{i j}\right)} \\
& C V(q)=\frac{s \tan \text { dard deviation }\left(Q_{i j}\right)}{\text { Average }\left(Q_{i j}\right)}
\end{aligned}
$$

The decision rule that aid the choice of model was define as Choose the Additive model if

$|C V(q)|\rangle|C V(d)|$

Choose the Multiplicative model if

$$
|C V(q)| \leq|C V(d)|
$$

\section{Method of seasonal variance of the buys- ballot table}

Iwueze and Nwogu [13] using Table 1 when $M_{t}=a+b t$ obtained the following results for the additive and multiplicative models

$$
\hat{\sigma}_{. j}^{2}=\left\{\begin{array}{l}
b^{2}\left(\frac{n(n+s)}{12}\right), \text { for additive model } \\
{\left[b^{2}\left(\frac{n(n+s)}{12}\right)\right] S_{j}^{2}, \text { for multiplicative model }}
\end{array}\right.
$$

Iwueze and Nwogu [13] proposed the following tests for additivity

$$
H_{0}: \sigma_{.1}^{2}=\sigma_{.2}^{2}=\ldots=\sigma_{s}^{2}
$$

Against the alternative;

$H_{1}: \sigma_{. j}^{2} \neq \sigma_{. j^{\prime}}^{2}$, for at least one $j \neq j^{\prime}$

Parametric tests (see Bartlett test [1]; Cochran test [6]; Hartley test [11]; Levene test [15]; O'Brien test [16] and non-parametric tests ( non-parametricLevene test (Nordstokke and Zumbo [16]; BrownForsythe test [3]; Flighner- Killeen test [10]; Square Rank test [7] for equality of variance assume random sample, independence within sample, mutual independence andmeasurement scale is at least interval. However, for time series data, all these tests are violated except for measurement scale at interval. Hence, the parametric and non-parametric tests for equality of variance ought to be compared in terms of power and robustness. Another critical point with this proposal has to do with the case when there is no trend $(b=0)$ because the seasonal variances of Equation (5.1) are zero. This proposal ought to be looked at to compensate for cases where there is no trend in a series and for comparison of the methods in order to determine power and robustness.

\section{Empirical examples}

In this paper, simulated and real life data will be use to demonstrate the three methods described above.

\subsection{Simulations of both additive and multiplicative se- ries}

In this paper, one hundred (100) random digits of length one hundred and twenty (120) from a normal distribution $\left(e_{t} \sim N(0,1)\right)$ were simulated and used for additive series simulation. Also one hundred (100) random digits of length one hundred and twenty (120) from a normal distribution $\left(e_{t} \sim N(1,0.09)\right)$ were simulated and used for multiplicative series simulation.

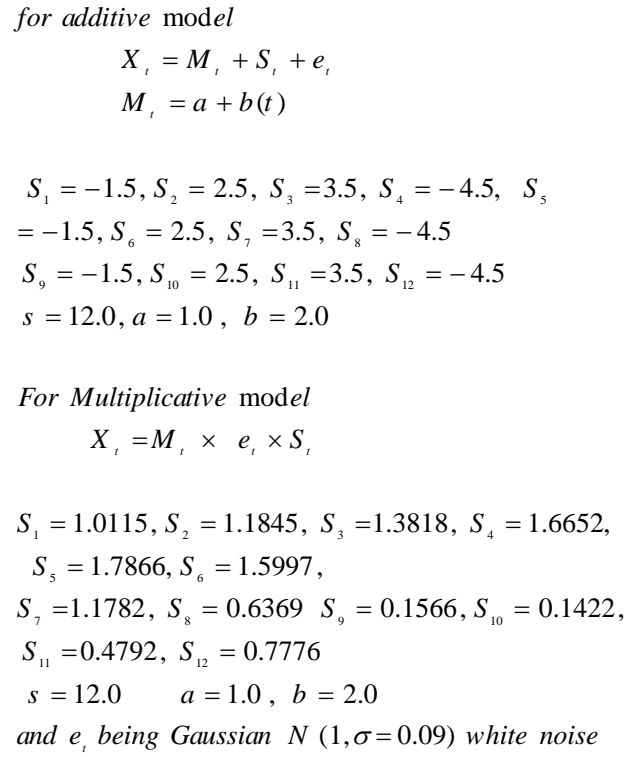




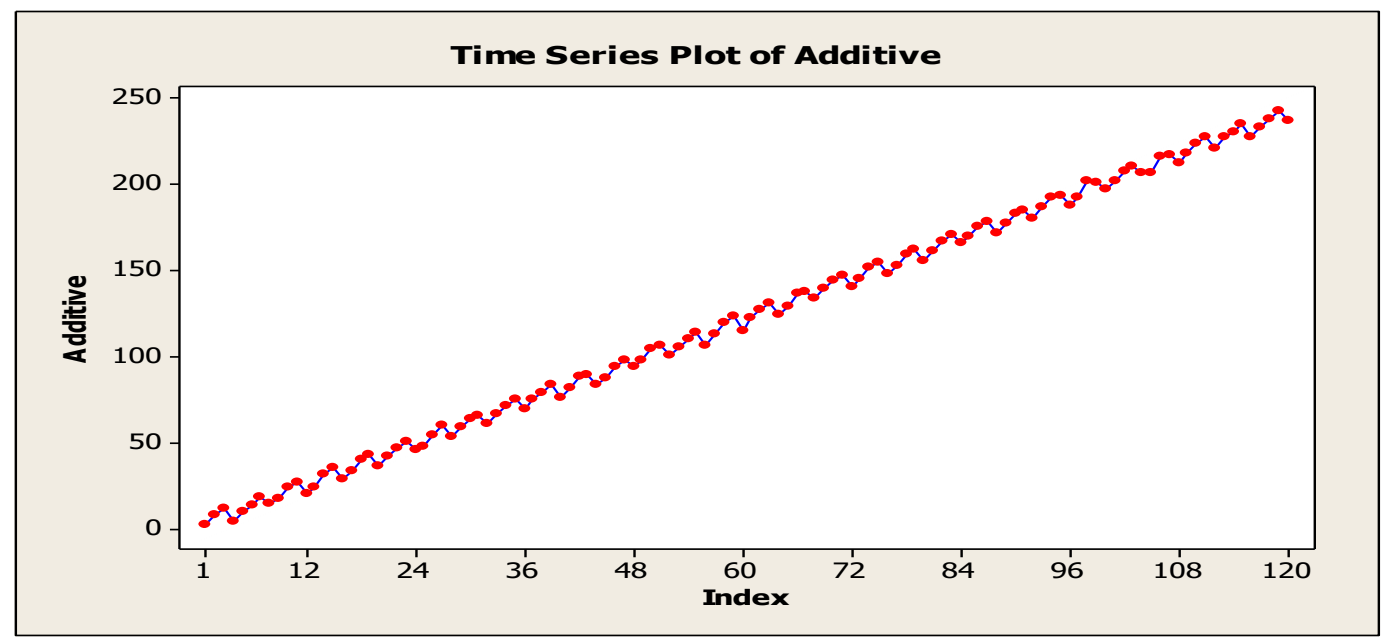

Fig. 1: Original Plot of simulated Additive Series.

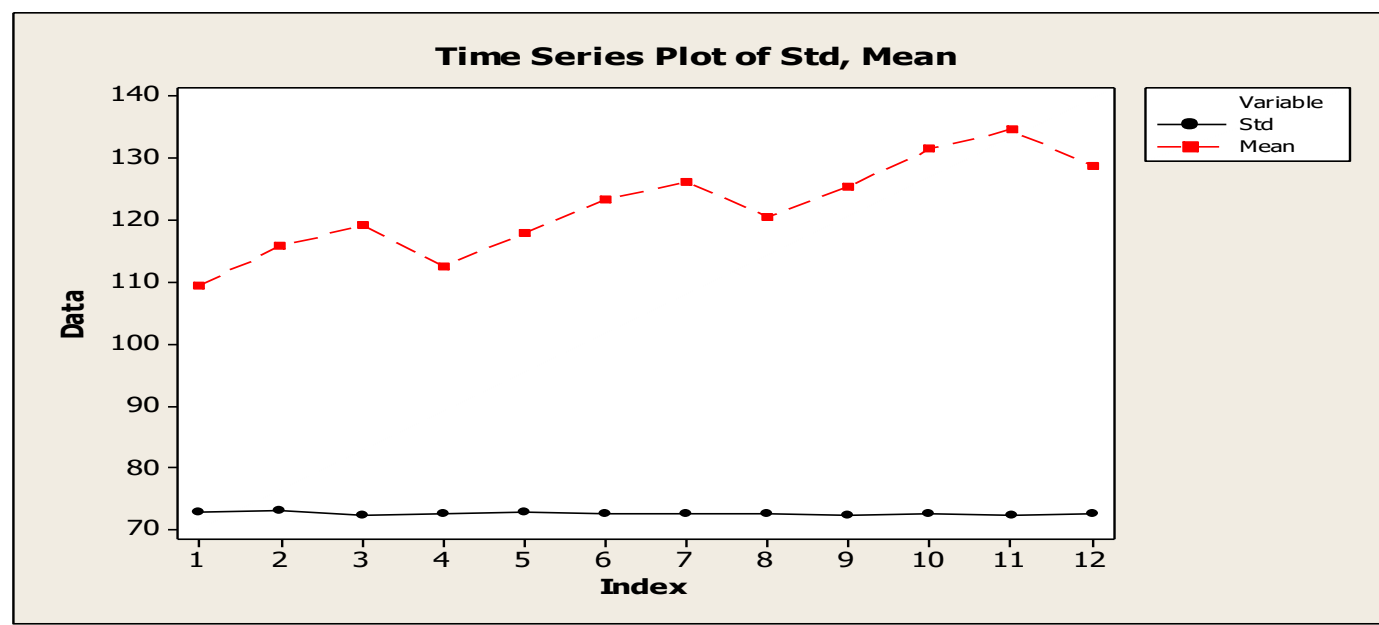

Fig. 2:Buys-Ballot Plot of Simulated Additive Series for Seasonal Standard Deviation and Mean.

The above plot of the original series shows that the seasonal variations remain the same regardless of the trend level. This shows that the appropriate model for decomposition is the additive model. The time plot of other series not shown in this paper follows similar pattern when the series is additive.

Figure 2 above show the Buys-Ballot method propose by Iwueze et al [12]. From the plot above, the seasonal standard deviation shows no appreciable increase/decrease with respect to any increase/decrease in the seasonal means. Hence the appropriate model for decomposition is the additive model. The plots of other series not shown in this paper also follows similar pattern when the series is additive

X-12 Method for Simulated Additive Series

D 8.AF-tests for seasonality (Multiplicative Decomposition)

Test for the presence of seasonality assuming stability.

\begin{tabular}{|c|c|c|c|}
\hline Sum of & Dgrs.of & Mean & \\
\hline $\begin{array}{c}\text { Squares } \\
4212.52\end{array}$ & $\begin{array}{l}\text { Freedom } \\
\quad 11\end{array}$ & $\begin{array}{l}\text { Square } \\
382.95\end{array}$ & $\begin{array}{l}\text { F-value } \\
6084.47 * *\end{array}$ \\
\hline 9253.96 & 108 & 85.68 & \\
\hline 13466.48 & 119 & & \\
\hline
\end{tabular}

$\begin{array}{llll}\text { Residual } & 9253.96 & 108 & 85.68 \\ \text { Total } & 13466.48 & 119 & \end{array}$

**Seasonality present at the 0.1 per cent level.

D 8.AF-tests for seasonality (Additive Decomposition)

Test for the presence of seasonality assuming stability.

$$
\begin{array}{llll}
\text { Sum of } & \text { Dgrs.of } & \text { Mean } & \\
\text { Squares } & \text { Freedom } & \text { Square } & \text { F-Value }
\end{array}
$$

$\begin{array}{lllll}\text { Between months } & 1235.15 & 11 & 112.29 & 140.17 * *\end{array}$

$\begin{array}{lrrr}\text { Residual } & 86.52 & 108 & 0.80\end{array}$

Total $\quad 1321.67 \quad 119$

**Seasonality present at the 0.1 per cent level.
The results obtained when the method of X-12 decomposition was applied to the simulated additive series show that the model using the additive decomposition has a more stable seasonal F-Value compared to the model using multiplicative decomposition since the F-value of the additive decomposition is greater than the Fvalue of the multiplicative decomposition. Other simulated series using the above method show similar results.

The results obtained when the method of coefficient of variation of the seasonal differences and quotients were applied to the simulated additive series show that the appropriate choice of model for decomposition is the additive model as the seasonal quotients were all greater than the seasonal differences (see Table 2). The results for additive series (6-99) not shown in Table 2 also gave similar results.

The time plot of Figure 3 of the original series show that the seasonal variation increases as the trend level increases. The plot shows that the appropriate model for decomposition is the multiplicative model. The time plot of other series not shown in this paper follows similar pattern when the series is multiplicative.

Figure 4 below show the Buys-Ballot method propose by Iwueze et al. [12]. From the plot below, the seasonal standard deviation shows appreciable increase/decrease with respect to increase/decrease in the seasonal means. Hence the appropriate model for decomposition is the multiplicative model. The plots of other series not shown in this paper also follows similar pattern when the series is multiplicative 
Table 2: Summary of Results for Seasonal Differences and Quotients

\begin{tabular}{|c|c|c|c|c|}
\hline \multicolumn{5}{|c|}{ Simulated Additive Series } \\
\hline Series & Seasonal Difference (SD) & $\begin{array}{l}\text { Seasonal } \\
\text { Quotients (SQ) }\end{array}$ & $\begin{array}{l}\text { Decision Rule: } \\
\text { Additive iff }|S Q| \geq|S D|\end{array}$ & Remark \\
\hline 1 & 0.061 & 0.721 & $\mathrm{SQ}>\mathrm{SD}$ & Additive \\
\hline 2 & 0.057 & 0.832 &, & Additive \\
\hline 3 & 0.061 & 0.765 & , & Additive \\
\hline 4 & 0.059 & 0.729 & 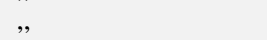 & Additive \\
\hline 5 & 0.055 & 1.484 & , & Additive \\
\hline . & . & . & . & \\
\hline · & . & $\cdot$ & . & \\
\hline 100 & 0.064 & 0.594 & $\mathrm{SQ}>\mathrm{SD}$ & Additive \\
\hline
\end{tabular}

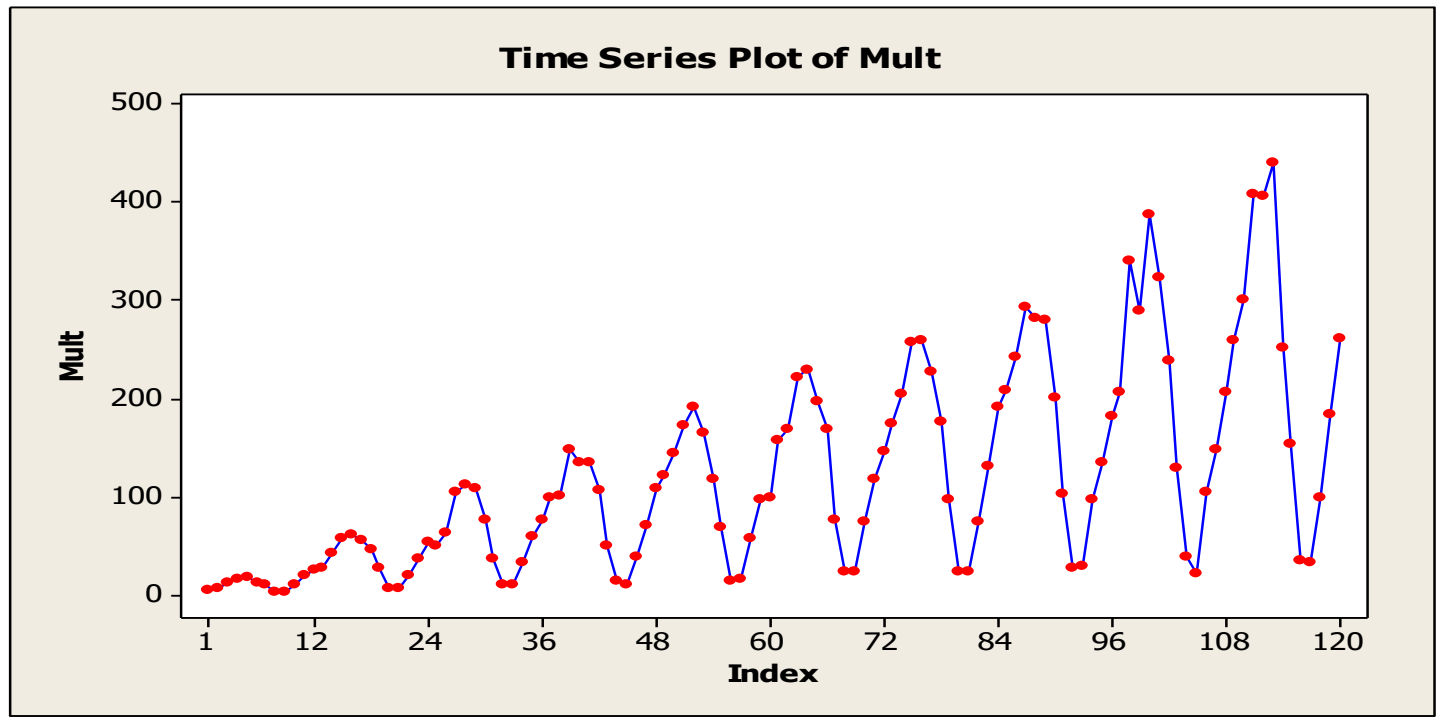

Fig. 3: Original Time Plot for Simulated Multiplicative Series.

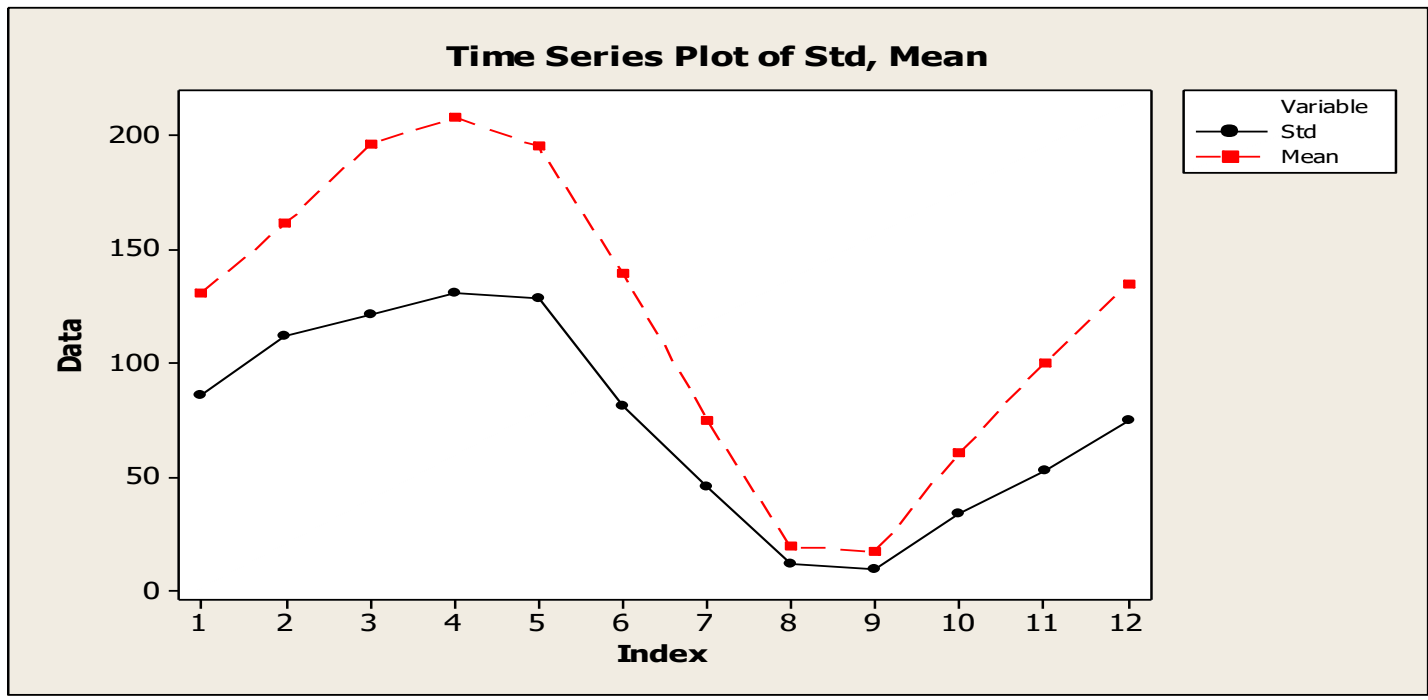

Fig. 4:Buys-Ballot Plot for Seasonal Standard Deviation and Mean.

X-12 Method for Simulated Multiplicative Series

D 8.AF-tests for seasonality (Multiplicative Decomposition)

Test for the presence of seasonality assuming stability.

Sum of Dgrs.of Mean

Squares Freedom Square F-Value

Between months $373937.89 \quad 11 \quad 33994.35 \quad 347.01 * *$

$\begin{array}{llll}\text { Residual } \quad 10580.14 & 108 & 97.96\end{array}$

Total $384518.03 \quad 119$

**Seasonality present at the 0.1 per cent level.

D 8.AF-tests for seasonality (Additive Decomposition \}

Test for the presence of seasonality assuming stability.
Sum of Dgrs.of Mean

Squares Freedom Square F-Value

Between months $541771.17 \quad 11 \quad 49251.92 \quad 33.46^{* *}$

$\begin{array}{llll}\text { Residual } & 158976.68 & 108 & 1472.01\end{array}$

Total $700747.84 \quad 119$

**Seasonality present at the 0.1 per cent level.

The results obtained when the method of X-12 decomposition was applied to the simulated multiplicative series shows that the model using the multiplicative decomposition has a more stable seasonal F-Value compared to the model using additive decomposition since the F-value of the multiplicative decomposition is greater than the F-value of the additive decomposition. Other simulated series using the above method gave similar results. 
Table 3: Summary of Results for Multiplicative Series

\begin{tabular}{|c|c|c|c|c|}
\hline \multicolumn{5}{|c|}{ Multiplicative Series } \\
\hline series & Seasonal Difference (SD) & Seasonal Quotients (SQ) & $\begin{array}{l}\text { Decision Rule: } \\
\text { Multiplicative iff }|S D|\rangle|S Q|\end{array}$ & Remark \\
\hline 1 & 0.976 & 0.592 & $\mathrm{SD}>\mathrm{SQ}$ & Multiplicative \\
\hline 2 & 0.954 & 0.648 & , & Multiplicative \\
\hline 3 & 0.942 & 0.604 &, & Multiplicative \\
\hline 4 & 0.912 & 0.614 & ", & Multiplicative \\
\hline . & . & . & . & \\
\hline 100 & 1.006 & 0.688 & $\dot{S D}>\mathrm{SQ}$ & Multiplicative \\
\hline
\end{tabular}

The results obtained when the method of seasonal differences and quotients were applied to the simulated multiplicative series show that the appropriate choice of model for decomposition is the series model as the seasonal quotients were all less than the seasonal differences (see Table 3 ). The results for multiplicative series (599) not shown in Table 3 also gave similar results.

\subsection{Using real life data}

Below is the descriptive analysis of time series applied to the quarterly sales of petroleum products from 2004-2013 (million naira). These data were collected from NNPC, River State as given in column 1 and 2 of Table 5.

The plot above shows that the seasonal variation stays roughly the same size regardless of the mean level. Hence the appropriate model for decomposition is the multiplicative model.
Applying the Buys-Ballot method, the column mean and standard deviation is shown in Table 8

Table 4: Column Means and Standard Deviation

\begin{tabular}{lll}
\hline s/n & Column Mean & Column Standard deviation \\
\hline 1 & 198.78 & 7.77 \\
2 & 187.3 & 10.05 \\
3 & 191.45 & 14.66 \\
4 & 195.01 & 17.76 \\
\hline
\end{tabular}

We can also see from the graphical representation of the column mean and standard deviation in Figure 6 show that the seasonal standard deviation shows applicable increase in relative to an increase in the seasonal means. Hence, the suitable model for decomposition is the multiplicative mode.

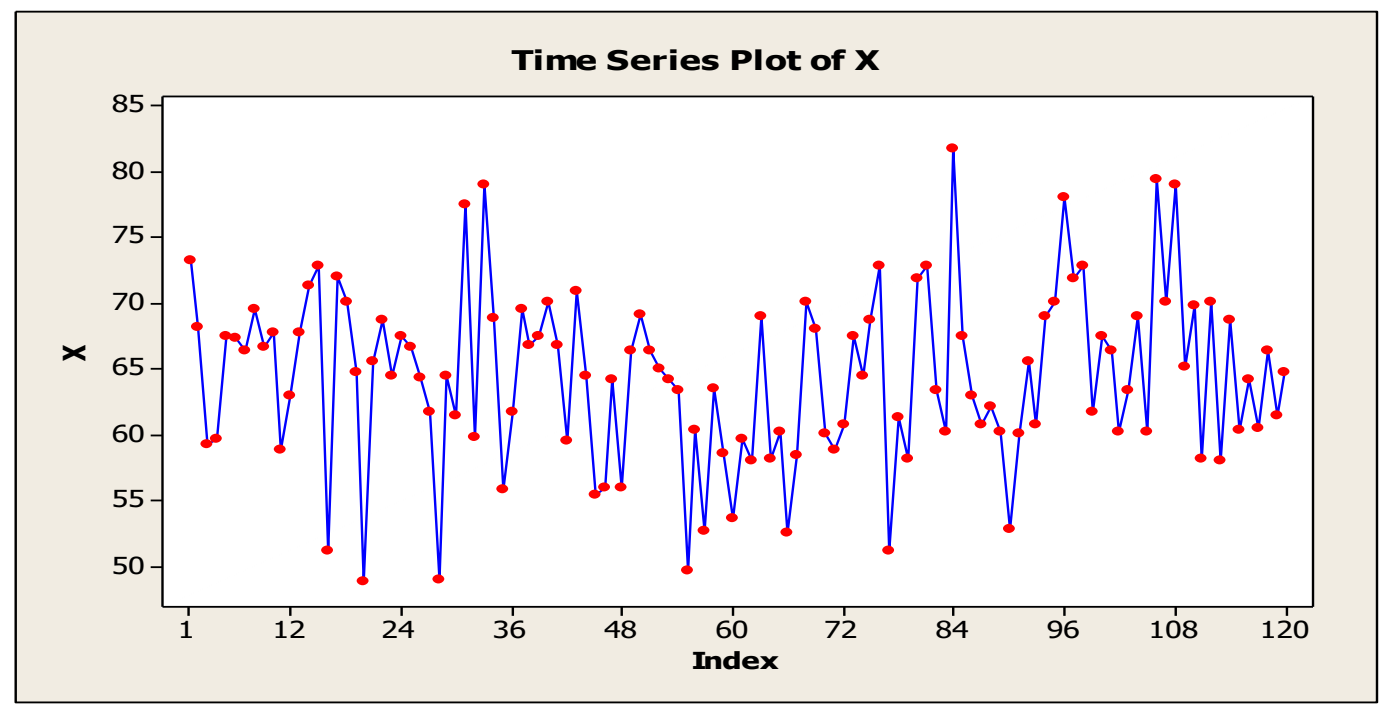

Fig. 5: Time Plot of the Original Series of Sales of Petroleum Product in River State.

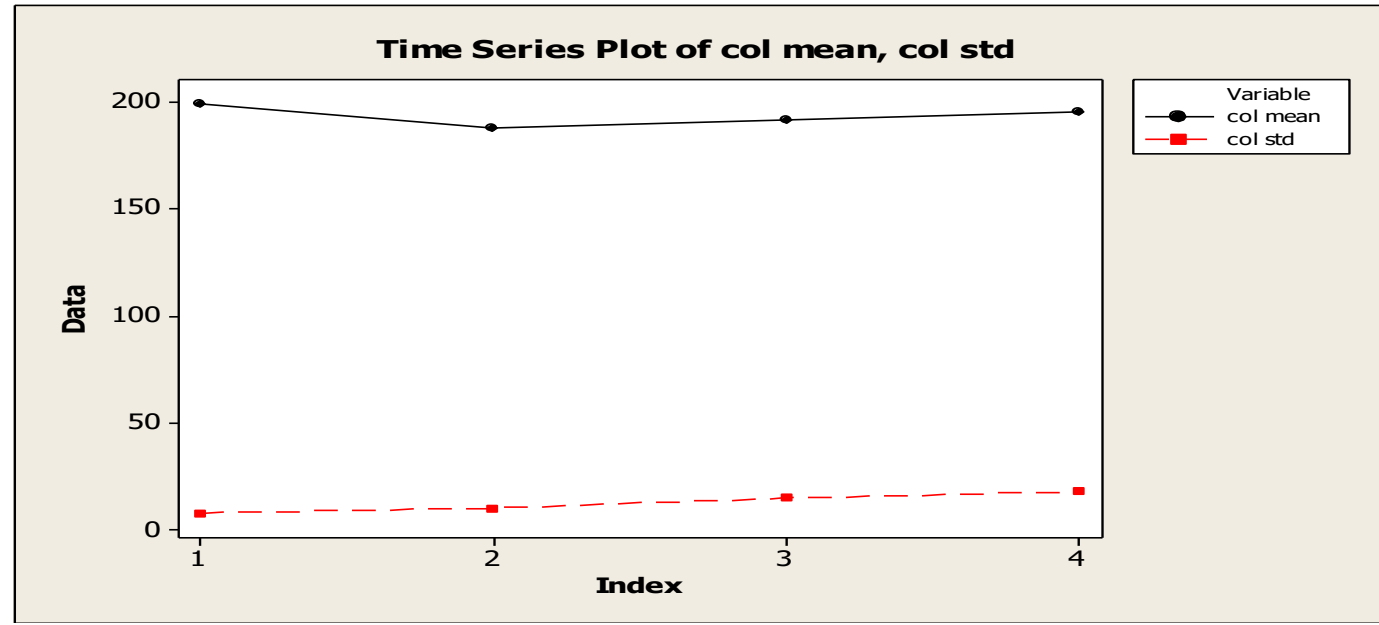

Fig. 6: Plot of Column Mean and Standard Deviation. 
TheX-12 Method solution of same data is given by

D 8.AF-tests for seasonality (Additive Model)

Test for the presence of seasonality assuming stability.

Sum of Dgrs.of Mean

Squares Freedom Square F-Value

$\begin{array}{lllll}\text { Between quarters } & 873.53 & 3 & 291.18 & 2.595\end{array}$

$\begin{array}{llll}\text { Residual } & 4039.60 & 36 & 112.21\end{array}$

Total $4913.13 \quad 39$

**Seasonality present at the 0.1 per cent level.

D 8.AF-tests for seasonality (Multiplicative Model)

Test for the presence of seasonality assuming stability.

$\begin{array}{lcccc} & \text { Sum of } & \text { Dgrs.of } & \text { Mean } & \\ & \text { Squares } & \text { Freedom } & \text { Square } & \text { F-Value } \\ \text { Between quarters } & 239.02 & 3 & 79.67 & 2.64 \\ \text { Residual } & 1085.38 & 36 & 30.15 & \\ \text { Total } & 1324.39 & 39 & & \\ \text { **Seasonality present at the } 0.1 \text { per cent level. }\end{array}$

The X-12 method also review a multiplicative model as the Fvalue for the multiplicative model is larger than that of the additive model.

Finally, applying the method of coefficient of variation of the seasonal differences and quotients, the result of the ratio of the absolute value of the standard deviation and average for the seasonal differences was greater than that of the seasonal quotients, thus indicating that the appropriate model for decomposition of the series is the multiplicative model.

The Seasonal quotient and difference is computed as followed

Table 5: Quarterly Sales of Petroleum Product

\begin{tabular}{|c|c|c|c|}
\hline Month/year & Price in Millions & Seasonal Difference & Seasonal quotient \\
\hline 2004/T1 & 200.48 & & \\
\hline $\mathrm{T} 2$ & 194.43 & & \\
\hline $\mathrm{T} 3$ & 202.5 & & \\
\hline 2005/T1 & 211.83 & 11.35 & 1.06 \\
\hline $\mathrm{T} 2$ & 193.16 & -1.27 & 0.99 \\
\hline $\mathrm{T} 3$ & 179.12 & -23.38 & 0.88 \\
\hline $\mathrm{T} 4$ & 200.52 & 11.1 & 1.06 \\
\hline 2006/T1 & 192.6 & -19.23 & 0.91 \\
\hline $\mathrm{T} 2$ & 174.83 & -18.33 & 0.91 \\
\hline $\mathrm{T} 3$ & 216.04 & 36.92 & 1.21 \\
\hline $\mathrm{T} 4$ & 186.35 & -14.17 & 0.93 \\
\hline 2007/T1 & 203.63 & 11.03 & 1.06 \\
\hline $\mathrm{T} 2$ & 196.34 & 21.51 & 1.12 \\
\hline $\mathrm{T} 3$ & 191.26 & -24.78 & 0.89 \\
\hline $\mathrm{T} 4$ & 175.55 & -10.8 & 0.94 \\
\hline 2008/T1 & 201.81 & -1.82 & 0.99 \\
\hline $\mathrm{T} 3$ & 162.60 & -28.66 & 0.85 \\
\hline $\mathrm{T} 4$ & 175.55 & 0 & 1.00 \\
\hline 2009/T1 & 186.61 & -15.2 & 0.92 \\
\hline $\mathrm{T} 2$ & 170.74 & -21.76 & 0.87 \\
\hline $\mathrm{T} 3$ & 196.46 & 33.86 & 1.21 \\
\hline $\mathrm{T} 4$ & 179.56 & 4.01 & 1.02 \\
\hline 2010/T1 & 200.52 & 13.91 & 1.07 \\
\hline $\mathrm{T} 2$ & 185.30 & 14.56 & 1.09 \\
\hline $\mathrm{T} 3$ & 202.8 & 6.34 & 1.03 \\
\hline $\mathrm{T} 4$ & 205.33 & 25.77 & 1.14 \\
\hline 2011/T1 & 191.12 & -9.4 & 0.95 \\
\hline $\mathrm{T} 2$ & 175.07 & -10.23 & 0.94 \\
\hline T3 & 186.31 & -16.49 & 0.92 \\
\hline $\mathrm{T} 4$ & 216.92 & 11.59 & 1.06 \\
\hline 2012/T1 & 206.24 & 15.12 & 1.08 \\
\hline $\mathrm{T} 2$ & 193.95 & 18.88 & 1.11 \\
\hline $\mathrm{T} 3$ & 192.39 & 6.08 & 1.03 \\
\hline $\mathrm{T} 2$ & 196.64 & 2.69 & 1.01 \\
\hline $\mathrm{T} 3$ & 184.99 & -7.4 & 0.96 \\
\hline $\mathrm{T} 4$ & 192.56 & -35.82 & 0.84 \\
\hline Total & & -19.52 & 36.02 \\
\hline Standard deviation & & 17.78276 & 0.094686 \\
\hline Average & & -0.54222 & 1.000556 \\
\hline Stand./Average & & -32.7961 & 0.094633 \\
\hline
\end{tabular}

\section{Conclusion}

From the foregoing, it is important to check the characteristic of data before appropriate model is chosen for decomposition. The selection of a proper model is extremely important as it reflects the underlying structure of the series because the fitted model in turn is used for future forecasting. Three methods for the choice of model in descriptive time series were considered and used to identify the appropriate model for decomposition. The results of the three methods for choice of model for both real life and simulated data identified the appropriate model for decomposition. These methods are subjective and no test was provided to justify the 
decision rule. Hence there is need to provide alternative method that uses a statistical test to justify the reason for choice of model in descriptive time series.

\section{References}

[1] Bartlett M.S, (1937). Properties of sufficiency and statistical test, Proc. Roy SocSr.App 268-282

[2] Brockwell P.J and Davis R.A (2002). Introduction to Time Series and Forecasting $2^{\text {nd }}$ Edition, Springer New York.https://doi.org/10.1007/b97391.

[3] Brown, M.B \& Forsythe, A.B. (1974). Robust tests for equality of variances. Journal of the American Statistical Association 69: 364 367. https://doi.org/10.1080/01621459.1974.10482955.

[4] Buys-Ballot,C.H.D. (1847) "Leo ClaemertPeriodiques de Temperature," Kemint et Fills, Utrecht.

[5] Chatfield C. (2004). The Analysis of Time Series: An Introduction, Chapman and Hall/CRC Press, Boca Raton.

[6] Cochran W.G (1947). Some consequences when the assumptions for the analysis of variance are not satisfied. Biometrics, 3: 2238https://doi.org/10.2307/3001535.

[7] Conover W.J (1999). Practical nonparametric Statistics, $3^{\text {rd }}$ ed., John Wiley and Sons, New York.

[8] Dagum, E. B. (1983). The X-12 Seasonal Adjustment Method, Technical Report 12-564E, Statistics Canada.

[9] Findley D.F., Monsell B.C., Bell W.R., Otto M.C., and Chen B.C (1998). New Capabilities and Methods of the X-12 ARIMA Seasonal Adjustment Program. Journal of Business \& Economic Statistics, 16(2), 127-152.

[10] Fligner, M. \& Killeen, T. (1976). Distribution-Free Two-Sample Tests for Scale: Journal of American Statistical Association. 71(353)

210 212.https://doi.org/10.1080/01621459.1976.10481517.

[11] Hartley, H.O., (1950). The maximum F-ratio as a short-cut test of heterogeneity of variance, Biometrika, 37, 308312.https://doi.org/10.2307/2332383.

[12] Iwueze I.S, Nwogu E.C, Ohakwe J. and Ajaraogu J.C (2011). Uses of the Buys-Ballot Table in Time Series Analysis, Applied Mathematics, pp 633-645.https://doi.org/10.4236/am.2011.25084.

[13] Iwueze I.S and Nwogu E.C, (2014). Framework for Choice of Model and Detection of Seasonal Effect in Time Series. Far East Journal of Theoretical Statistics, Vol. 48 No. 1, pp 45-66.

[14] Justo P. and Rivera M.A., (2010). Descriptive analysis of Time Series applied to housing prices in Spain, Management Mathematics for European Schools, 94342-CP-1-2001-DE-COMENIUS-C21

[15] Levene H., (1960). Robust test for equality of variance, Contribution to Probability and Statistics, I. Olkin, S.G. Ghury, W. Hoeffding, W.G. Madow and H.B Mann, eds, Stanford Univ. Press, Stanford, pp 275-292

[16] Nordstokke, D. W \&Zumbo, B. D. (2010). A New Nonparametric Levene test for Equal Variance. Journal of Psicologica, 31, 401430.

[17] O'Brien, R.G. (1979). A General ANOVA Method for Robust Tests of Additive Models for Variances. Journal of the American Statistical Association, 877 880.https://doi.org/10.1080/01621459.1979.10481047.

[18] Shiskin J., Young A.H., and Musgrave J.C. (1967). The X-11 variant of the Census method II seasonal adjustment program. Technical Paper 15, Bureau of the Census, U.S Department of Commerce.

[19] Wei W. W. S. (1989). Time Series Analysis: Univariate and Multivariate Methods, Addison-Wesley, Redwood City. 